\title{
Pluripotent and Multipotent Stem Cells and Current Therapeutic Applications: Review
}

This article was published in the following Dove Press journal:

Stem Cells and Cloning: Advances and Applications

Misganaw Gebrie Worku (D)

Department of Human Anatomy, University of Gondar, College of Medicine and Health Science, School of Medicine, Gondar, Ethiopia
Correspondence: Misganaw Gebrie Worku

Email misgeb2008@gmail.com
Abstract: There is numerous evidence for the presence of stem cells, which is important for the treatment of a wide variety of disease conditions. Stem cells have a great therapeutic effect on different degenerative diseases through the development of specialized cells. Embryonic stem (ES) cells are derived from preimplantation embryos, which have a natural karyotype. This cell has the capacity of proliferation indefinitely and undifferentiated. Stem cells are very crucial for the treatment of different chronic and degenerative diseases. For instance, stem cell clinical trials have been done for ischemic heart disease. Also, the olfactory cells for spinal cord lesions and human fetal pancreatic cells for diabetes mellitus are the other clinical importance of stem cell therapy. Extracellular matrix (ECM) and other environmental factors influence the fate and activity of stem cells.

Keywords: stem cell, embryonic stem cell, adult stem cell, stem cell therapy

\section{Introduction}

Stem cells have excellent tissue regeneration and repair capacity, which is used in the production of drugs and regenerative medicine depends on the discovery of viable sources of multipotent and pluripotent cells. ${ }^{1}$ For clinical applications pathogen-free human embryonic stem cells (ESC) and successful differentiation techniques are important. ${ }^{1,2}$ The therapeutic potential of embryonic stem cells in the development of specialized cells to replace damaged tissue in patients with variable degenerative diseases. ${ }^{3}$ However, the signaling pathways for the adoption of different cellular phenotypes involved in lineage restriction of ESC are still not clear. ${ }^{3}$ Besides, as ESC-based therapies advance towards clinical applications, an appropriate culture environment must be established to create a genetically stable homogeneous cell population through the prevention of adverse effects of transplantation. ${ }^{3,4}$ Until differentiating into the more advanced cells, which gives specialized tissues, embryonic stem cells are present in the embryo. ${ }^{5}$

\section{Embryonic Stem Cell}

Embryonic stem cells are derived from preimplantation embryos, which are capable of indefinite and undifferentiated proliferation. Besides, primate ES cells retain their ability to distinguish between trophoblast and embryonic endoderm, mesoderm, and ectoderm derivatives. ${ }^{6}$ Since these cells have the differentiation capacity to almost all cells or tissue, they have a good advantage to cure several diseases, including diabetes mellitus, Alzheimer's, anemia and spinal cord injuries. ${ }^{7}$ Embryonic stem cells can be obtained from the embryo via processes called reproductive cloning. 
The main problem with reproductive cloning is the inducement of the immune system as it is not genetically similar to the donor cells. ${ }^{8}$ As a result of scientific advancement in the area of stem cell research, more genetically compatible cells will be produced. ${ }^{9}$ These features make ESC an attractive regenerative medicine cell source, which is used to restore damaged tissue and cells lost due to disease. ${ }^{9,10}$ In animal models, various ESCbased therapies have shown promise and some of them are now in clinical trials in humans. ${ }^{9,11}$ However, in terms of processing, packaging, quality control and protection, the generation of ESC lines and their derivatives for cellular therapies pose specific challenges. In culture, they may be extended while maintaining the functional properties of early embryo cells that are pluripotent. ${ }^{6,9,12}$

This has stimulated interest in the isolation of human origin analogous cells. ${ }^{6}$ These human pluripotent stem cells may be a renewable source of more differentiated cells that could be used for cellular transplantation. ${ }^{13,14}$ The number of available human ES cell lines for study may also be inadequate to assess their therapeutic potential. ${ }^{14}$ However, recent molecular and cellular developments in mouse ES cells represent the active use of these cells in therapeutics. ${ }^{14,15}$ In developed nations since the funding for human embryonic stem cells is limited, many scientists use the animal model. Murine and embryonic cells can regenerate themselves and split into a cell of all forms. ${ }^{16,17}$

\section{Induced Pluripotent Stem Cell}

Induced pluripotent stem (iPS) cells are derived from adult somatic cells, which are genetically reprogrammed by forced gene expression to an embryonic stem and are essential for preserving the defining properties of ES cells. ${ }^{18}$ Reprogrammed induced pluripotent cell enables the development of an unlimited source of cells. ${ }^{19,20}$ IPS cells are identical to ES cells that have similar cell marker expression features. ${ }^{21}$

\section{Adult Stem Cell}

Stem cell clinical trials are performed for ischemic heart disease and to assist with bone non-union. ${ }^{22}$ The olfactory cells for spinal cord lesions and human fetal pancreatic cells for type 1 diabetes are other adult stem cells applied in clinical trials. ${ }^{22,23}$ These cells are limited in their ability to give various types of cells and are thus multipotent types of cells, while scientists are seeking a way to overcome this benefit. The multipotent cell of the brain derivate is very crucial for the treatment of Parkinson's disease. ${ }^{24,25}$ It is clearly stated that there is an abundance of bone marrow-derived stem cells, which are used for different therapeutic purposes. $^{26,27}$ Furthermore, stem cells are used for the treatment of the heart problem, which can become cardiac myocytes and neuroprogenitor cells have been identified within the brain, which was previously thought to be devoid of stem cells. $^{28}$

\section{Fate of Pluripotent and Multipotent Cells}

Adult stem cells are responsible for replacing differentiated cells in continuously regenerating tissues, like in the liver, skin and blood system. ${ }^{29,30}$ A broad range of environmental factors related to the overall regulation of stem cell development. ${ }^{31}$ In particular, new data continue to focus on the effect of the extracellular matrix (ECM) on stem cell fates through physical interactions with cells. ${ }^{31}$ Another study reported that stem cell fate can be affected by extracellular matrices. ${ }^{31}$ In addition to physical shape modulation, certain subsets of these effects arise from altered adhesive interactions between the cell and the substrate. $^{31,32}$ Many extrinsic and intrinsic factors interact to affect cell structure, including long-term interactions with the microenvironment of cells, as well as changes due to physical factors like mechanical or osmotic stress. $^{31-33}$

Several studies have recently revealed that the geometric microenvironment plays an important role in stem cell fate regulation. Aside from the mechanical properties of scaffolds, pore sizes, porosity, surface stiffness, and mechanical stimulation may also influence stem cell fate. ${ }^{34}$ Chemical factors such as cell-adhesive ligands and exogenous growth factors will also control the fate of stem cells. ${ }^{34}$ To have a more complex and regulated scaffold cell, it is very crucial to have a good understanding of the physical and chemical signals that affect the fate of stem cell. ${ }^{34,35}$ Generally, multipotent stem cells stay quiet while keeping their place in the stem cell pool without differentiating. ${ }^{17}$ The formation of two daughter cells from cell division, ${ }^{36,37}$ the division into two cells, ${ }^{17,37,38}$ or separation of a stem cell from the parent cell to produce two daughters are the potential fate of stem cell differentiation. ${ }^{39}$ Until differentiating into more advanced progenitor cells, it produces multiple folds of cells in a systematic way. ${ }^{40,41}$ 


\section{Stem Cell Differentiation}

Differentiation of stem cells entails transforming a cell into a more specific type of cell, which involves changes in cellular structure, signal reactivity, and other factors. ${ }^{42}$ The ability of stem cells to divide and differentiate is greatly affected by changes in their signaling pathways and gene expression. ${ }^{43,44}$

There are different types of stem cells based on their ability to differentiate: totipotent, pluripotent, and multipotent cells. Besides, Oligopotent differentiates into a few different types of cells, whereas Unipotent differentiates only one type of cell. ${ }^{16}$ Generally, the cell aggregates and aggregated cells spontaneously divide when stem cells are cultured without an adherent surface, feeder cells. ${ }^{45}$

\section{Embryonic Stem Cell Differentiation}

Embryonic stem cells are originated from blastocyst-stage embryos' inner cell mass. ${ }^{46}$ They can be preserved and expanded in culture as pure populations of undifferentiated cells for prolonged periods. ${ }^{16}$ In contrast to transformed tumor cell lines, ES cells preserve normal karyotypes after extensive passage in culture. ${ }^{1}$ The ability to differentiate embryonic stem cells into different types of cells opens the door to new mammalian growth models and regenerative medicine cell sources. ${ }^{3}$ It is critical to control ESC differentiation to realize this potential and guide the production of these cells along specific pathways. ${ }^{47,48}$

\section{Adult Stem Cell Differentiation}

In a different type of adult tissue, stem cells produce new cells continuously or in response to injury. ${ }^{30}$ However, some distinct populations of multipotent cells can develop additional cell types under certain conditions. ${ }^{49,50}$ Differentiation of stem cells is triggered by both physical and chemical signals. ${ }^{17}$ Stem cells may be guided to neuronal, myogenic, or osteogenic lineages through the adjustment of the stiffness of the substrate ${ }^{17}$ Since cells can be mature in both physical and chemical environments, a combination of the two would likely be sufficient for optimal stem cell differentiation. ${ }^{17,51}$ Efficient and structured protocols must be developed before stem cells can be used therapeutically, ensuring that cells are a wellcontrolled and well-defined entity. ${ }^{52}$

\section{Stem Cell Therapy}

For almost half a century the successful application of hematopoietic stem cells in hematopoietic transplants has prompted attempts to employ stem cells in treating many other clinical issues, including weakened myocardium after heart infarction, brain after stroke and spinal cord after mechanical injury. ${ }^{22,23,53}$ As stem cells can give additional potential cells, which have tremendous potential for tissue regeneration and reconstruction for medical application. The most and commonly used stem cell treatment is the transplant of blood stem cells to treat diseases and disorders of the blood and immune system. ${ }^{54}$ The United States' national marrow donor program has a long list of diseases that can be treated with blood stem cell transplantation. The transplantation of healthy, active, and propagating cells to restore the function of deficient tissues is referred to as cell therapy. Selfrenewal and the ability to distinguish differentiated cells are two characteristics of stem cells. ${ }^{22,55}$

\section{Embryonic Stem Cell}

The potential of ES for self-renewal and differentiation has opened up the prospect of widespread use in regenerative research and medicine. ${ }^{5}$ If these cells are rendered immune-compliant with the recipient, they can solve the problems of donor tissue shortages and implant rejection. ${ }^{5,56}$ Cell therapy is an increasingly appealing notion in modern transplantation medicine. ${ }^{5}$ For several clinical problems, the replacement of missing cells would be the ideal cure. ${ }^{5}$ These include progressive cell loss diseases associated with age (various types of congestive heart failure, degenerative brain diseases, and sarcopenia), traumatic tissue loss and death of iatrogenic cells. ${ }^{53}$

\section{Adult Stem Cells}

Currently, there is more advanced progress in the use of bone marrow derivatives to treat different pathological problems. ${ }^{57}$ Many other disorders and health conditions are expected to benefit from multipotent cell therapy in the upcoming future. Stem cells extracted from bone marrow are in clinical trials to remedy heart ailments. ${ }^{17}$

\section{Induced Pluripotent Stem Cells}

Induced pluripotent stem cells (iPSCs) are commonly used in disease modeling, regenerative medicine and drug development. ${ }^{58}$ Induced pluripotent stem cells have a wide range of uses in gene therapy, disease modeling and drug development. ${ }^{59}$ Despite the need for further research, researchers are concentrate on the potential usefulness of iPSCs as a method for drug discovery, disease modeling and transplantation medicine. ${ }^{59}$ The idea that 
a patient's tissues could have a plentiful supply of immune-matched pluripotent cells has piqued the interest of researchers and clinicians all over the world. Furthermore, ethical concerns about ESC processing do not extend to iPSCs, which provide a non-controversial way to produce patient-specific stem cell lines. ${ }^{60}$

\section{Conclusion}

There are many expectations for stem cell treatment of human diseases, but many problems still need to be addressed. In the beginning, more advanced work should be done on embryonic and adult human stem cells, since there is a great biological difference between these laboratory mice and human cells. The other important issue that should be considered is that the shared characteristics and features of the uncontrolled division of cancer and stem cells, which may be very crucial to prevent many problems that are associated with extensive stem cell division. Besides, unique protocols must be developed to improve the growth, survival and integration of transplanted cells. Finally, clinical trials must be conducted to ensure the safety and efficacy of stem cell therapy. When it comes to stem cells, understanding they exist is a long way from using them therapeutically.

\section{Disclosure}

The author reports no conflict of interest in this work.

\section{References}

1. Polak JM. Advances in Tissue Engineering. Imperial College Press; 2008.

2. Clarke D, Frisén J. Differentiation potential of adult stem cells. Curr Opin Genet Dev. 2001;11(5):575-580. doi:10.1016/S0959-437X(00) $00235-5$

3. Liu Z, Zhang Q-B, Bu C, et al. Quantitative dynamics of proteome, acetylome, and succinylome during stem-cell differentiation into hepatocyte-like cells. J Proteome Res. 2018;17(7):2491-2498. doi:10.1021/acs.jproteome. 8 b00238

4. Barfoot J. What diseases and conditions can be treated with stem cells. 2017.

5. He Q, Li J, Bettiol E, Jaconi ME. Embryonic stem cells: new possible therapy for degenerative diseases that affect elderly people. J Gerontol. 2003;58(3):M279-M87. doi:10.1093/gerona/58.3.M279

6. Smith AG. Embryo-derived stem cells: of mice and men. Annu Rev Cell Dev Biol. 2001;17(1):435-462. doi:10.1146/annurev. cellbio.17.1.435

7. Grskovic M, Javaherian A, Strulovici B, Daley GQ. Induced pluripotent stem cells - opportunities for disease modelling and drug discovery. Nat Rev Drug Discov. 2011;10(12):915-929. doi:10.1038/nrd3577

8. Herberts CA, Kwa MS, Hermsen HP. Risk factors in the development of stem cell therapy. J Transl Med. 2011;9(1):1-14. doi:10.1186/14795876-9-29
9. Klimanskaya I, Kimbrel EA, Lanza R. Chapter 23 - embryonic stem cells. In: Lanza R, Langer R, Vacanti JP, Atala A, editors. Principles of Tissue Engineering. Fifth ed. Academic Press; 2020:421-434.

10. Teo AK, Vallier L. Emerging use of stem cells in regenerative medicine. Biochem J. 2010;428(1):11-23. doi:10.1042/BJ20100102

11. Chapman AR, Scala CC. Evaluating the first-in-human clinical trial of a human embryonic stem cell-based therapy. Kennedy Inst Ethics J. 2012;22(3):243-261. doi:10.1353/ken.2012.0013

12. Kehat I, Kenyagin-Karsenti D, Snir M, et al. Human embryonic stem cells can differentiate into myocytes with structural and functional properties of cardiomyocytes. J Clin Invest. 2001;108(3):407-414. doi:10.1172/JCI200112131

13. Bradley JA, Bolton EM, Pedersen RA. Stem cell medicine encounters the immune system. Nat Rev Immunol. 2002;2(11):859-871. doi:10.1038/nri934

14. Wobus AM, Boheler KR. Embryonic stem cells: prospects for developmental biology and cell therapy. Physiol Rev. 2005;85(2):635-678. doi:10.1152/physrev.00054.2003

15. Hildebrand MS, Newton SS, Gubbels SP, et al. Advances in molecular and cellular therapies for hearing loss. Mol Ther. 2008;16 (2):224-236. doi:10.1038/sj.mt.6300351

16. Keller G. Embryonic stem cell differentiation: emergence of a new era in biology and medicine. Genes Dev. 2005;19(10):1129-1155. doi:10.1101/gad.1303605

17. Biehl JK, Russell B. Introduction to stem cell therapy. J Cardiovasc Nurs. 2009;24(2):98. doi:10.1097/JCN.0b013e318197a6a5

18. de Figueiredo Pessôa LV, Bressan FF, Freude KK. Induced pluripotent stem cells throughout the animal kingdom: availability and applications. World J Stem Cells. 2019;11(8):491. doi:10.4252/wjsc. v11.i8.491

19. Yamanaka S. Induced pluripotent stem cells: past, present, and future. Cell Stem Cell. 2012;10(6):678-684. doi:10.1016/j.stem.2012.05.005

20. Lalit PA, Hei DJ, Raval AN, Kamp TJ. Induced pluripotent stem cells for post-myocardial infarction repair: remarkable opportunities and challenges. Circ Res. 2014;114(8):1328-1345. doi:10.1161/ CIRCRESAHA.114.300556

21. Ye L, Swingen C, Zhang J. Induced pluripotent stem cells and their potential for basic and clinical sciences. Curr Cardiol Rev. 2013;9 (1):63-72. doi:10.2174/157340313805076278

22. Shortt AJ, Tuft SJ, Daniels JT. Corneal stem cells in the eye clinic. $B r$ Med Bull. 2011;100(1):209-225. doi:10.1093/bmb/ldr041

23. Tuch BE. Stem cells: a clinical update. Aust Fam Physician. 2006;35 (9):719.

24. Weiss ML, Medicetty S, Bledsoe AR, et al. Human umbilical cord matrix stem cells: preliminary characterization and effect of transplantation in a rodent model of Parkinson's disease. Stem Cells. 2006;24(3):781-792. doi:10.1634/stemcells.2005-0330

25. Salaris F, Rosa A. Construction of 3D in vitro models by bioprinting human pluripotent stem cells: challenges and opportunities. Brain Res. 2019;1723:146393. doi:10.1016/j.brainres.2019.146393

26. King C. New insights into the differentiation and function of T follicular helper cells. Nat Rev Immunol. 2009;9(11):757-766. doi:10.1038/nri2644

27. Mimeault M, Hauke R, Batra SK. Stem cells: a revolution in therapeutics - recent advances in stem cell biology and their therapeutic applications in regenerative medicine and cancer therapies. Clin Pharmacol Ther. 2007;82(3):252-264. doi:10.1038/sj.clpt.6100301

28. Biehl JK. The Physical Microenvironment Regulates Embryonic Stem Cells. Chicago: University of Illinois; 2008.

29. Rawlins EL, Hogan BL. Epithelial stem cells of the lung: privileged few or opportunities for many? Development. 2006;133 (13):2455-2465. doi:10.1242/dev.02407

30. Moshaverinia A, Xu X, Chen C, et al. Application of stem cells derived from the periodontal ligament or gingival tissue sources for tendon tissue regeneration. Biomaterials. 2014;35(9):2642-2650. doi:10.1016/j.biomaterials.2013.12.053 
31. Guilak F, Cohen DM, Estes BT, Gimble JM, Liedtke W, Chen CS Control of stem cell fate by physical interactions with the extracellular matrix. Cell Stem Cell. 2009;5(1):17-26. doi:10.1016/j. stem.2009.06.016

32. Parker KK, Ingber DE. Extracellular matrix, mechanotransduction and structural hierarchies in heart tissue engineering. Philos Transact Royal Soc B. 2007;362(1484):1267-1279. doi:10.1098/ rstb.2007.2114

33. Lane SW, Williams DA, Watt FM. Modulating the stem cell niche for tissue regeneration. Nat Biotechnol. 2014;32(8):795-803. doi:10.1038/nbt.2978

34. Xing F, Li L, Zhou C, et al. Regulation and directing stem cell fate by tissue engineering functional microenvironments: scaffold physical and chemical cues. Stem Cells Int. 2019;2019:1-16. doi:10.1155/ 2019/2180925

35. Bratt-Leal AM, Carpenedo RL, McDevitt TC. Engineering the embryoid body microenvironment to direct embryonic stem cell differentiation. Biotechnol Prog. 2009;25(1):43-51. doi:10.1002/ btpr. 139

36. Clevers H, Watt FM. Defining adult stem cells by function, not by phenotype. Annu Rev Biochem. 2018;87:1015-1027. doi:10.1146/ annurev-biochem-062917-012341

37. Marciniak-Czochra A, Stiehl T, Ho AD, Jäger W, Wagner W. Modeling of asymmetric cell division in hematopoietic stem cellsregulation of self-renewal is essential for efficient repopulation. Stem Cells Dev. 2009;18(3):377-386. doi:10.1089/scd.2008.0143

38. Spit M, Koo B-K, Maurice MM. Tales from the crypt: intestinal niche signals in tissue renewal, plasticity and cancer. Open Biol. 2018;8 (9):180120. doi:10.1098/rsob.180120

39. Chatzeli L, Simons BD. Tracing the dynamics of stem cell fate. Cold Spring Harb Perspect Biol. 2020;12(6):a036202. doi:10.1101/cshperspect.a036202

40. Weissman IL. Stem cells: units of development, units of regeneration, and units in evolution. Cell. 2000;100(1):157-168. doi:10.1016/ S0092-8674(00)81692-X

41. Kode JA, Mukherjee S, Joglekar MV, Hardikar AA. Mesenchymal stem cells: immunobiology and role in immunomodulation and tissue regeneration. Cytotherapy. 2009;11(4):377-391. doi:10.1080/ 14653240903080367

42. Galve-Roperh I, Chiurchiù V, Díaz-Alonso J, Bari M, Guzmán M, Maccarrone M. Cannabinoid receptor signaling in progenitor/stem cell proliferation and differentiation. Prog Lipid Res. 2013;52 (4):633-650. doi:10.1016/j.plipres.2013.05.004

43. Boquest AC, Shahdadfar A, Frønsdal K, et al. Isolation and transcription profiling of purified uncultured human stromal stem cells: alteration of gene expression after in vitro cell culture. Mol Biol Cell. 2005;16(3):1131-1141. doi:10.1091/mbc.e04-10-0949

44. Dayem AA, Choi HY, Yang GM, et al. The potential of nanoparticles in stem cell differentiation and further therapeutic applications. Biotechnol J. 2016;11(12):1550-1560. doi:10.1002/biot.201600453
45. Karp JM, Ferreira LS, Khademhosseini A, Kwon AH, Yeh J, Langer RS. Cultivation of human embryonic stem cells without the embryoid body step enhances osteogenesis in vitro. Stem Cells. 2006;24(4):835-843. doi:10.1634/stemcells.2005-0383

46. Biehl JK, Russell B. Introduction to stem cell therapy. J Cardiovasc Nurs. 2009;24(2):98-105.

47. Murry CE, Keller G. Differentiation of embryonic stem cells to clinically relevant populations: lessons from embryonic development. Cell. 2008;132(4):661-680. doi:10.1016/j. cell.2008.02.008

48. Cheng ZA. Biological Multi-Functionalization and Surface Nanopatterning of Biomaterials. Université Sciences et Technologies-Bordeaux I; Université catholique de Louvain; 2013.

49. Hall PA, Watt FM. Stem cells: the generation and maintenance of cellular diversity. Development. 1989;106(4):619-633.

50. Ding S, Kingshott P, Thissen H, Pera M, Wang PY. Modulation of human mesenchymal and pluripotent stem cell behavior using biophysical and biochemical cues: a review. Biotechnol Bioeng. 2017;114(2):260-280. doi:10.1002/bit.26075

51. Yang C. Dynamic Control of Synthetic Hydrogels to Understand hMSCs Differentiation and Mechanotransduction. Boulder: University of Colorado; 2015.

52. Pamies D, Bal-Price A, Chesné C, et al. Advanced good cell culture practice for human primary, stem cell-derived and organoid models as well as microphysiological systems. ALTEX. 2018;35(3):353-378.

53. Boiani M, Schöler HR. Regulatory networks in embryo-derived pluripotent stem cells. Nat Rev Mol Cell Biol. 2005;6(11):872-881. doi:10.1038/nrm1744

54. Weissman IL, Shizuru JA. The origins of the identification and isolation of hematopoietic stem cells, and their capability to induce donor-specific transplantation tolerance and treat autoimmune diseases. Blood. 2008;112(9):3543-3553.

55. Ofori-Acquah S, Ohene-Frempong K. Beyond national borders: a global perspective on advances in sickle cell disease research and management, and new challenges in the Genome Era. Renaissance of sickle cell disease research in the Genome Era. 2007.

56. Furth ME, Atala A. Current and Future Perspectives of Regenerative Medicine. San Diego: Academic Press; 2008.

57. Domen J, Wagers A, Weissman IL. Bone marrow (hematopoietic) stem cells. Regen Med. 2006;13.

58. Wu SM, Hochedlinger K. Harnessing the potential of induced pluripotent stem cells for regenerative medicine. Nat Cell Biol. 2011;13 (5):497-505. doi:10.1038/ncb0511-497

59. Goldthwaite CA. 10. The promise of induced pluripotent stem cells (iPSCs). 2008.

60. Singh VK, Kalsan M, Kumar N, Saini A, Chandra R. Induced pluripotent stem cells: applications in regenerative medicine, disease modeling, and drug discovery. Front Cell Dev Biol. 2015;3:2. doi:10.3389/fcell.2015.00002
Stem Cells and Cloning: Advances and Applications is an international, peer-reviewed, open access journal. Areas of interest in established and emerging concepts in stem cell research include: Embryonic cell stems; Adult stem cells; Blastocysts; Cordblood stem cells; Stem cell transformation and culture; Therapeutic cloning; Umbilical cord blood and bone marrow cells; Laboratory, animal and human therapeutic studies; Philosophical and ethical issues related to stem cell research. This journal is indexed on CAS. The manuscript management system is completely online and includes a very quick and fair peer-review system, which is all easy to use. Visit http://www.dovepress.com/testimonials.php to read real quotes from published authors. 